\title{
A new method for cryopreservation of mouse spermatozoa
}

\author{
L. M. Penfold ${ }^{*}$ and H. D. M. Moore ${ }^{* *}$ \\ Institute of Zoology, Zoological Society of London, Regent's Park, London NW1 4RY, UK
}

\begin{abstract}
A new method for the cryopreservation of mouse spermatozoa was developed using a modified egg-yolk TES-Tris diluent containing $0.1 \%$ sodium lauryl sulfate and $1.25 \%(\mathrm{v} / \mathrm{v})$ glycerol (mouse sperm cryoprotectant, MSC). Epididymal spermatozoa collected from 10week-old CBA males were frozen at a rate of $5^{\circ} \mathrm{C} \mathrm{min}{ }^{-1}$ to $4^{\circ} \mathrm{C}$ and $50^{\circ} \mathrm{C} \mathrm{min}^{-1}$ to $-70^{\circ} \mathrm{C}$ using a programmable cell freezer. A percentage of the spermatozoa $(25 \%)$ regained motility after thawing. In vitro fertilization with frozen-thawed spermatozoa resulted in $50 \%$ of oocytes developing to the two-cell stage. These two-cell embryos were placed in the oviducts of pseudopregnant recipients $(\mathrm{C} 57 \mathrm{BL} / \mathrm{CBA})$ and $16 \%$ developed to be viable fetuses, or in the oviducts of pregnant recipients (MF1) and 17\% developed to live offspring.
\end{abstract}

\section{Introduction}

In contrast to the cryopreservation of mouse embryos (Whittingham et al., 1972) and oocytes (Whittingham, 1977), the only report of successful cryopreservation of mouse spermatozoa was until recently the unpublished findings by Rapatz and Zimmerman (see Graham $e$ t al., 1978). These investigators artificially inseminated two groups of mice; 106 females with spermatozoa cryopreserved in skimmed milk and fructose diluent which resulted in the birth of nine young, and 84 females with spermatozoa cryopreserved in a skimmed milk and fructose diluent containing 1\% BSA and $4 \mathrm{mmol}$ calcium chloride $\mathrm{I}^{-1}$, which resulted in the birth of 61 young. With the dramatic increase in the use of transgenic mice there is now a greater urgency to develop methods for cryopreservation of male and female germ cells efficiently and this has led to renewed interest in improving mouse sperm cryopreservation. Tada et al. (1990), Yokoyama et al. (1990) and Okuyama et al. (1990) have indicated that mouse spermatozoa (from several strains) frozen in various combinations of raffinose and glycerol will regain motility after thawing, and when used in combination with in vitro fertilization and embryo transfer, live offspring have been produced. In this laboratory, despite repeated trials, we have been unable to obtain fertile mouse spermatozoa using these protocols. However, on screening other potential diluents with a cryomicroscope (L.M. Penfold, unpublished), consistent survival of mouse spermatozoa was obtained following freezing and thawing with a low $(1.25 \% \mathrm{v} / \mathrm{v})$ glycerol and egg yolk cryoprotectant.

Here, we report on the use of modified egg-yolk diluent containing glycerol and sodium lauryl sulfate (SDS) and designated mouse sperm cryoprotectant (MSC) medium. A proportion of

*Present address and correspondence: Germplasm and Gamete Physiology Laboratory, Beltsville Agricultural Research Center, USDA, Beltsville, MD 20705, USA.

${ }^{* *}$ Present address: University of Sheffield, Department of Obstetrics and Gynaecology, Jessop Hospital for Women, Leavygreave Road, Sheffield S3 7RE, UK.

Received 21 October 1992. spermatozoa from CBA mice suspended in this diluent retained motility after freezing and thawing and could be recovered from the medium for subsequent in vitro fertilization.

\section{Materials and Methods}

\section{Animals}

Three-week-old, C57Blk/6 $\times \mathrm{CBA} / \mathrm{CA} \mathrm{F}_{1}$ females were used as oocyte donors and 10-week-old CBA/CaBlk males as sperm donors (Bantin and Kingman Ltd, Grimston Aldrough, Hull).

Eight- to twelve-week-old C57Blk/6 $\times \mathrm{CBA} / \mathrm{CA} \mathrm{F}_{1}$ females and outbred MFI females (Harlan Olac Ltd, Shaw's Farm, Bicester) were used as foster recipients. Animals were housed at $22^{\circ} \pm 2^{\circ} \mathrm{C}, 50 \%$ relative humidity, $14 \mathrm{~h}$ light: $10 \mathrm{~h}$ dark cycle and fed on Rat and Mouse diet no. 1 (SDS, Witham, Essex) with continuous access to water. When necessary, females were mated with bilaterally vasectomized $\mathrm{CBA} / \mathrm{CaBlk}$ males so that they became pseudopregnant. Ten-week-old males were anaesthetized with an i.p. injection of $0.015-0.017 \mathrm{ml} 2.5 \%$ Avertin $\mathrm{g}^{-1}$ (Aldrich Chemicals, Gillingham) of body weight. Under sterile conditions, a midline abdominal incision was used to expose the vasa deferentia which were ligated and cut. The wound was closed with suture in the normal manner. These males were carefully checked for sterility before use.

\section{Mouse sperm cryoprotectant (MSC) medium}

Screening of various potential cryoprotectant solutions for mouse spermatozoa with the cryomicroscope (Penfold et al., unpublished) led to the formulation of MSC medium consisting of $21.07 \mathrm{mmol} \mathrm{N}$-tris [hydroxymethyl]methyl-2-aminoethane sulfonic acid (TES) $\mathrm{l}^{-1}, 9.49 \mathrm{mmol}$ tris $\mathrm{l}^{-1}, 2.22 \mathrm{mmol}$ glucose $1^{-1}, 1.25 \% \mathrm{v} / \mathrm{v}$ glycerol, $25 \% \mathrm{v} / \mathrm{v}$ egg yolk, $0.1 \%$ sodium lauryl sulfate (SDS) and $0.000125 \%$ streptomycin. The medium was prepared by the following method. Double distilled, deionised water ( $12 \mathrm{ml}$ ) was added to $4 \mathrm{ml}$ egg yolk and $0.1 \%$ sodium lauryl sulfate. The solution was mixed thoroughly and left for 
$30 \mathrm{~min}$ before centrifuging at $20000 \mathrm{~g}$ for $1 \mathrm{~h}$. To $8 \mathrm{ml}$ of supernatant was added $0.483 \mathrm{~g}$ TES, $0.115 \mathrm{~g}$ Tris, $0.04 \mathrm{~g}$ glucose, $0.01 \mathrm{~g}$ streptomycin and $100 \mu \mathrm{l}$ glycerol. The final osmolarity was approximately $675 \mathrm{mosmol}$. Cryoprotectant was stored at $4^{\circ} \mathrm{C}$ for up to 3 days.

\section{Freezing protocol}

Four adult male mice (10-weeks-old) were killed by cervical dislocation and their caudae epididymides without vasa deferentia were removed and placed into $1 \mathrm{ml}$ of cryoprotectant at $30^{\circ} \mathrm{C}$. Spermatozoa were released by cutting the epididymides and agitating gently. The spermatozoa were dispersed throughout the cryoprotectant by gently pipetting up and down using a Pasteur pipette for $30 \mathrm{~s}$. Aliquots, $200 \mu \mathrm{l}$, were transferred to $1.8 \mathrm{ml}$ polypropylene cryotubes (Nunc, Paisley) which were then placed in a programmable cell freezer ( $\mathrm{R} 204$, Planer Products Ltd, Sunbury) at $30^{\circ} \mathrm{C}$. Preliminary studies using the cryomicroscope indicated that the optimal freezing regimen consisted of an initial rate of $5^{\circ} \mathrm{C} \mathrm{min}{ }^{-1}$ to $4^{\circ} \mathrm{C}$, then $50^{\circ} \mathrm{C}$ $\min ^{-1}$ to $-70^{\circ} \mathrm{C}$. The cryotubes were subsequently immersed directly in liquid nitrogen and transferred to a storage vessel for a minimum of $24 \mathrm{~h}$.

\section{Thawing protocol}

Cryotubes were immersed in water at $37^{\circ} \mathrm{C}$ until the medium thawed and the sample was transferred to an incubator at $37^{\circ} \mathrm{C}$, $5 \% \mathrm{CO}_{2}$ and equilibrated for $10 \mathrm{~min}$. Most of the MSC medium was removed by centrifuging for $4 \mathrm{~min}$ at $800 \mathrm{~g}$, removing the supernatant and resuspending the pellet in $500 \mu \mathrm{l}$ T6 medium (Quinn et al., 1982) containing $15 \mathrm{mg} \mathrm{BSA} \mathrm{ml}^{-1}$ (fraction V, Sigma Chemical Co., St Louis). The sperm suspension was placed in an incubator at $37^{\circ} \mathrm{C}$ in an atmosphere of $5 \% \mathrm{CO}_{2}$ in air. The MSC supernatant was subjected to a further centrifugation at $12000 \mathrm{~g}$ for $5 \mathrm{~min}$ to remove any residual spermatozoa and used as a negative control (see below).

\section{In vitro fertilization experiments}

$\mathrm{C} 57 \mathrm{BL} / \mathrm{CBA} \mathrm{F}_{1}$ females were superovulated for use as oocyte donors and $\mathrm{CBA}$ males were used as donors of fresh and frozen spermatozoa. In vitro fertilization followed a standard procedure with animals and media prepared according to the methods of Glenister et al. (1987). Oocytes were collected $14 \mathrm{~h}$ after hCG injection in T6 medium under oil. Frozen-thawed spermatozoa (prepared as described above) were diluted to a concentration of $1 \times 10^{6}$ motile cells $\mathrm{ml}^{-1}$ in $300 \mu \mathrm{l} \mathrm{T6}$ medium plus BSA under oil and left to capacitate for $2 \mathrm{~h}$ from the time of thawing before they were incubated with fresh oocytes (within cumulus) for $4 \mathrm{~h}$ under oil. Oocytes were then washed three times in M16 medium containing $4 \mathrm{mg} \mathrm{BSA} \mathrm{ml}^{-1}$ before they were incubated overnight at $37^{\circ} \mathrm{C}$ in $5 \% \mathrm{CO}_{2}$ in air in $100 \mu \mathrm{l}$ of M16 medium. Oocytes were incubated with fresh (unfrozen) spermatozoa diluted in T6 medium containing $15 \mathrm{mg} \mathrm{BSA} \mathrm{m}^{-1}$ and transferred to M16 medium containing $4 \mathrm{mg} \mathrm{BSA} \mathrm{ml}{ }^{-1}$ before incubating overnight as a positive control. In addition, oocytes were incubated with medium alone or with medium containing $50 \mu \mathrm{l}$ MSC supernatant recovered following centrifugation of the frozen-thawed spermatozoa as described above.
Table 1. Development to two-cell of mouse oocytes incubated with fresh or frozen-thawed spermatozoa

\begin{tabular}{lccc}
\hline Experiment & $\begin{array}{c}\text { Number of } \\
\text { oocytes }\end{array}$ & $\begin{array}{c}\text { Number of } \\
\text { two-cell } \\
\text { embryos }\end{array}$ & $\% \pm$ SEM \\
\hline Frozen-thawed & & & \\
$\quad$ spermatozoa & 708 & 355 & $50 \pm 4.9^{*}$ \\
Fresh spermatozoa & 490 & 375 & $77 \pm 3.7$ \\
Cryoprotectant control & 324 & 56 & $17 \pm 3.6$ \\
\hline
\end{tabular}

*Significantly different from fresh spermatozoa $(P<0.05)$.

\section{Embryo transfer experiments}

After fertilization with frozen-thawed or fresh spermatozoa and incubation in vitro for $24 \mathrm{~h}$, two-cell embryos (six to ten) were transferred to the oviducts of day 1 pseudopregnant (C57BL/CBA) and pregnant (MF1) females according to the methods of Glenister et al. (1987).

On day 15 of pregnancy (day of transfer, day 1), C57BL/ CBA females were killed by cervical dislocation and implantation sites and fetuses counted. MFI females were allowed to go to term and brown offspring were distinguished from the natural albino litter.

\section{Results}

\section{Preparation of spermatozoa}

A high percentage $(80 \%)$ of epididymal spermatozoa in the MSC medium displayed lateral tail beating but no progressive motility before freezing. This was considered to be due to the relatively high osmolarity of the medium $(650-700 \mathrm{mosmol})$ affecting the pattern of flagellum beat. After freezing and thawing and then removal from the cryoprotectant, about $25 \%$ of spermatozoa exhibited progressive motility.

\section{In vitro fertilization with fresh and frozen spermatozoa}

Of the oocytes incubated with frozen-thawed spermatozoa $50 \pm 4.9 \%$ developed to the two-cell stage compared with a rate of $77 \pm 3.7 \%$ for oocytes with fresh spermatozoa (Table 1). Oocytes not inseminated with spermatozoa, but incubated in the presence of cryoprotectant diluted with T6 medium, showed an activation rate to two-cell of $17 \pm 3.6 \%$ compared with a background activation rate of $\leqslant 2 \%$ for oocytes incubated with medium alone. Of the oocytes incubated with frozen-thawed spermatozoa (Table 2), $39 \pm 4.9 \%$ developed to the morula/blastocyst stage compared with $56 \pm 4.5 \%$ for oocytes incubated with fresh spermatozoa (Table 2). None of the activated control oocytes developed beyond the two-cell stage.

In pseudopregnant females, the implantation rate was $36 \pm 0.71 \%$ and the fetal development rate $16 \pm 0.25 \%$ for oocytes fertilized with frozen-thawed spermatozoa (Table 3). Seventeen per cent of embryos instilled in pregnant foster mice 
Table 2. Development of mouse embryos to morula/blastocyst stage following in vitro fertilization with fresh and frozen-thawed spermatozoa

\begin{tabular}{lcccc}
\hline Experiment & $\begin{array}{c}\text { Number of } \\
\text { oocytes }\end{array}$ & $\begin{array}{c}\text { Number of } \\
\text { two-cell } \\
\text { embryos }\end{array}$ & $\begin{array}{c}\text { Number of } \\
\text { morulae/ } \\
\text { blastocysts }\end{array}$ & $\% \pm$ SEM \\
\hline Frozen-thawed spermatozoa & 312 & 159 & 121 & $39 \pm 4.9^{*}$ \\
Fresh spermatozoa & 324 & 249 & 181 & $56 \pm 4.5$ \\
\hline
\end{tabular}

*Significantly different from fresh spermatozoa $(P<0.05)$.

Table 3. Oviductal transfer of two-cell mouse embryos following in vitro fertilization with fresh and frozen-thawed spermatozoa

\begin{tabular}{lccc}
\hline & $\begin{array}{c}\text { Number of } \\
\text { embryos } \\
\text { transferred }\end{array}$ & $\begin{array}{c}\text { Number } \\
\text { implanted }\end{array}$ & $\begin{array}{c}\text { Number of } \\
\text { fetuses or } \\
\text { liveborn } \\
(\%)\end{array}$ \\
\hline $\begin{array}{l}\text { Fxperiment } \\
\begin{array}{l}\text { Pseudopregnant } \\
\text { Pregnant }\end{array}\end{array}$ & 98 & $35(36 \pm 0.71)^{*}$ & $16(16 \pm 0.25)$ \\
$\begin{array}{l}\text { Fresh spermatozoa } \\
\text { Pseudopregnant }\end{array}$ & 58 & $63(68 \pm 0.95)$ & $34(37 \pm 0.52)$ \\
\hline
\end{tabular}

*Significantly different from fresh spermatozoa $(P<0.05)$.

resulted in live offspring. For oocytes fertilized with fresh spermatozoa, an implantation rate of $69 \pm 0.95 \%$ and a fetal development rate of $37 \pm 0.52 \%$ were obtained.

Offspring derived from oocytes fertilized with frozenthawed spermatozoa were mated to check for fertility. Both male and female offspring had fertile matings resulting in normal litter sizes.

\section{Discussion}

After freezing and thawing in MSC medium, a proportion of spermatozoa from CBA mice retained their motility and fertilizing capacity. In vitro fertilization with cryostored spermatozoa resulted in the formation of viable two-cell embryos which when transferred to suitable recipients developed to form normal fetuses and live offspring. This technique was consistently successful, although the final number of offspring produced from each batch of in vitro fertilization was low. In contrast, in this laboratory (L. M. Penfold, unpublished observation) it has not been possible to obtain fertile spermatozoa cryopreserved using raffinose-glycerol diluent (Tada et al., 1990; Yokoyama et al., 1990; Okuyama et al., 1990).

Several characteristics of the MSC medium probably contribute to the survival of mouse spermatozoa during the freezing and thawing process. First, compared with other cryo-diluents, the relatively low glycerol concentration may have minimized any possible toxic effect on mouse spermatozoa, while still exerting an antifreeze action by sequestering free intracellular water (Mazur et al., 1970). Second, the egg yolk probably protects the spermatozoa during freezing by binding to the sperm plasmalemma (see Watson, 1975, 1981). With the electron microscope, we observed egg-yolk lipid closely associated with the sperm membrane (unpublished observation). This cryoprotective action of egg yolk during cooling and freezing has been well documented by Kampschmidt et al. (1953); Blackshaw (1954) and Pace and Graham (1974). The hyperosmolarity of the cryoprotectant may also have contributed to the survival of spermatozoa by removing intracellular water available for potential lethal ice formation. As a result, the spermatozoa were not progressively motile in the cryoprotectant, although they still moved from side to side. SDS was included in the cryoprotectant to solubilize the egg yolk and allow the recovery of the spermatozoa from the cryoprotectant after thawing. If during preparation of the cryoprotectant, SDS was added before the egg yolk was centrifuged, more motile spermatozoa survived freezing than when cryoprotectant was prepared by adding SDS after the egg yolk had been centrifuged (L. M. Penfold, unpublished observation). This would indicate that, in this instance, the detergent was not acting directly on the sperm plasmalemma, but was solubilizing the protective lipids in the egg yolk (Helenius and Simons, 1975; Arriola and Foote, 1987). A high level of egg activation occurred when unfertilized oocytes were mixed with cryoprotectant recovered from the freezing preparation. Exposure to cryoprotectant has been demonstrated to activate oocytes (Shaw and Trounson, 1989) in some but not all cases (Whittingham, 1977). Thus, residual cryoprotectant or products from dead spermatozoa present in the frozen-thawed spermatozoa sample at the time of 
fertilization might have induced premature activation of some oocytes, thereby preventing fertilization. This would account for the failure of some embryos to develop beyond the two-cell stage. This activation rate could be reduced by further removal of the cryoprotectant with additional centrifugation. However, this also led to increased damage to the frozen-thawed spermatozoa and thus poor recovery of motile cells.

Fewer oocytes were fertilized after incubation with frozenthawed spermatozoa than for those incubated with fresh spermatozoa. Although the concentration of spermatozoa added to the fertilization drop was adjusted for motility to $1 \times 10^{-6} \mathrm{ml}^{-1}$, dead spermatozoa present in the sample may have impeded viable spermatozoa from reaching the oocyte or may have reduced the survival rate of spermatozoa. As yet we have not developed a method for the elimination of dead spermatozoa. Swim-up methods proved ineffectual owing to the high numbers of immotile cells. Although the proportion of embryos that implanted was less for eggs fertilized with frozen-thawed spermatozoa than for those fertilized with fresh spermatozoa, post-implantation losses were similar for both groups ( $54 \%$ versus $46 \%$ ). It is anticipated that the cryopreservation of mouse spermatozoa in conjunction with the established techniques for oocytes and embryos will provide greater flexibility for genetic management of laboratory mouse strains and lead to new methods for cryopreservation of spermatozoa in other rodent species.

The authors thank W. V. Holt for his help with the cryomicroscope and M. J. Wood and C. Candy (E.E.T.U., St Georges Hospital Medical School) for guidance with embryo transfers. This study was supported in part by Planer Products Ltd.

\section{References}

Arriola J and Foote RH (1987) Glycerolation and thawing effects on bull spermatozoa frozen in detergent-treated egg yolk and whole egg extenders Journal of Dairy Science 70 1664-1670

Blackshaw AW (1954) The prevention of temperature shock of bull and ram spermatozoa Australian Journal of Biological Science 7 573-582
Glenister PH, Wood MJ, Kirby C and Whittingham DG (1987) Incidence of chromosome anomalies in first-cleavage mouse embryos obtained from frozen/thawed oocytes fertilised in vitro Gamete Research 16 205-216

Graham EF, Schmehl MKL, Evenson BK and Nelson DS (1978) Artificial Breeding of Non-Domestic Animals Symposia of the Zoological Society of London 43 196-209

Helenius A and Simons K (1975) Solubilisation of membranes by detergents Biochimica Biophysica Acta $\mathbf{4 1 5}$ 29-34

Kampschmidt RF, Mayer DT and Herman HA (1953) Lipid and lipoprotein constituents of egg yolk in the resistance and storage of bull spermatozoa Joumal of Dairy Science 36 733-742

Jones R and Mann T (1977) Damage to ram sperm by peroxidation of exogenous lipids Journal of Reproduction and Fertility 50 255-260

Mazur P, Leibo SP, Farrant J, Chy EHY, Hanna MG and Smith LH (1970) Interactions of cooling rate, warming rate and protective additive on the survival of frozen mammalian cells. In The Frozen Cell CIBA Foundation Symposium, pp 69-78 Eds GEW Wolstenholme and M O'Connor. Churchill, London

Okuyama M, Isogai S, Saga M, Hamada H and Ogawa S (1990) In vitro fertilisation (IVF) and artificial insemination (AI) by cryopreserved spermatozoa in mice Journal of Fertility and Implantation 7 116-119

Pace MM and Graham EF (1974) Components in egg yolk which protect bovine spermatozoa during freezing Journal of Animal Science 39 1144-1149

Quinn P, Barros C and Whittingham DG (1982) Preservation of hamster oocytes to assay fertilising capacity of human spermatozoa Journal of Reproduction and Fertility 66 161-168

Shaw JM and Trounson AO (1989) Parthenogenetic activation of unfertilized mouse oocytes by exposure to 1,2-propanediol is influenced by temperature, oocyte age and cumulus removal Gamete Research 24 269-279

Tada N, Sato J, Yamanoi T, Kasai K and Ogawa S (1990) Cryopreservation of mouse spermatozoa in the presence of raffinose and glycerol joumal of Reproduction and Fertility $89511-516$

Watson PF (1975) The protection of ram and bull spermatozoa by the low density lipoprotein fraction of egg yolk during storage at $5^{\circ} \mathrm{C}$ and deep freezing Journal of Thermal Biology 1 137-141

Watson PF (1981) The roles of lipid and protein in the protection of ram spermatozoa at $5^{\circ} \mathrm{C}$ by egg-yolk lipoprotein Joumal of Reproduction and Fertility 62 483-492

Whittingham DG (1977) Fertilization and development to term of unfertilised mouse oocytes previously stored at $-196^{\circ} \mathrm{C}$ Journal of Reproduction and Fertility 49 89-94

Whittingham DG, Leibo SP and Mazur P (1972) Survival of mouse embryos frozen to $-196^{\circ} \mathrm{C}$ and $-296^{\circ} \mathrm{C}$ Science $178411-414$

Yokoyama M, Akiba H, Katsuki M and Nomura T (1990) Production of normal young following transfer of mouse embryos obtained by in vitro fertilization using cryopreserved mouse spermatozoa Experimental Animals 39 $125-128$ 